\title{
Production of durable and cost effective sewer pipes using petroleum and industrial waste by- products
}

\author{
Maisa El Gamal ${ }^{*}$, Amr El-Dieb ${ }^{2}$, Khaled El-Sawy ${ }^{3}$, Amr Sweedan ${ }^{2}$ and Abdel-Mohsen \\ Mohamed ${ }^{4}$ \\ ${ }^{1}$ Assistant Professor, University College, Zayed University, Abu Dhabi, P.O. Box, 144534, Abu \\ Dhabi, UAE \\ ${ }^{2}$ Professor, Civil and Environmental Engineering Department - United Arab Emirates University, \\ P.O. Box 15551, Al Ain, UAE \\ ${ }^{3}$ Professor, Architecture Department - Effat University P.O. Box 34689, Jeddah, KSA \\ ${ }^{4}$ Associate Provost and Chief Academic Officer, Zayed University P.O. Box, 144534, Abu Dhabi, \\ UAE
}

\begin{abstract}
The Arabian Gulf environment has an adverse impact on concrete structures because of the high ambient temperature, humidity, salt contaminated dust, sea water and underground salts. As an innovative solution, reinforced modified sulfur concrete (MSC) pipes are recognized as a durable and economical solution for deterioration of pipelines. This work describes the manufacture and characterization of new MSC based on a cost effective sulfur modification process. Bitumen, a by-product from crude oil refining process was used to modify elemental sulfur and enhance its physical, mechanical properties, and mostly to increase its corrosive resistivity. The study has focused on optimizing the proportions of an offered MSC mixes that are composed of modified sulfur (MS) as a binder, crushed sand, dune sand and ladle furnace (LF) slag as aggregates, and ground granulated blast furnace slag (GGFBS) as a filler. To maximize the physical and mechanical properties of MSC sewer pipes, different mixtures were prepared and investigated. The optimum mix of MSC has a maximum compressive strength of $64 \mathrm{MPa}$, maximum splitting tensile strength of 4.5 $\mathrm{MPa}$, maximum flexural strength of $21 \mathrm{MP}$, with a high corrosion resistance in acidic and salty environments.
\end{abstract}

\section{Introduction}

These Improving concrete durability in sewerage systems against attack by strong mineral acids and salts can be accomplished by using modified sulfur concrete (MSC). The MSC is a thermoplastic composite concrete consisting of chemically modified sulfur polymer and aggregates [1]. The product is a building material with a smooth surface that is easy to design and sets much faster than normal concrete. The MSC produced from waste materials is corrosion resistant to harsh environments and impervious to moisture infiltration [2]. MSC

*Corresponding author: maisa.elgamal@zu.ac.ae 
has many industrial applications such as sidewalks and road blocks, construction of drainage and sewage facilities, basic coverage foundation, making the acid tanks, manufacturing and repairing concrete platforms, etc. [3, 4]. Research and development of MSC are in advance to discover possible usage of elemental sulfur present in many nations as a by-product of the oil and gas industry. The MSC produced from waste materials is corrosion-resistant and impervious to moisture infiltration.

Process of the sulfur concrete manufacturing is based on the "hot" technology in which all the mixed components are heated until $140-150^{\circ} \mathrm{C}$. The sulfur used in sulfur concrete production can be mixed with any type of traditional aggregate. Quantity should be optimized according to practical criteria as well as the mechanical properties [3]. When sulfur and aggregate are hot-mixed and cooled to produce sulfur concrete, the liquid sulfur binder initially crystallizes to monoclinic sulfur ( $\mathrm{Sb}$ ). As it continues to cool, the material goes through a solid phase transition to orthorhombic sulfur $(\mathrm{Sa})$, which causes the material to shrink in volume [5]. This reduction in volume creates internal stress and causes durability problems, especially when exposed to freeze thaw cycling. The modification of elemental sulfur suppresses the crystalline phase change that occurs upon sulfur cooling below $95.6^{\circ} \mathrm{C}$ from monoclinic to orthorhombic forms with a significant increase in density and internal stresses. Such residual stresses contribute to failure of elemental sulfur concrete products by impact or thermal change. Mixing elemental sulfur with a suitable thermoplastic material preferably a polyolefin prevents the residual stresses build-up between sulfur crystals, which causes the elemental sulfur concrete material to crack. While the phase transformation still occurs during sulfur cooling, the polymer acts as an acquiescent layer between sulfur crystals, thereby overcoming the drawback of elemental sulfur concrete products. [6, 7].

At present, a great deal of research and innovation are being conducted in many countries including United Arab Emirates [8], USA, Canada, Poland and Russia where building materials such as sulfur concrete and sulfur asphalt have been used because these materials are environmental friendly and cost effective [9]. Studying the effect of different proportions of MSC on physical and mechanical properties of MSC is relatively difficult due to the complexity and number of variables in this system. To this end, in the current study, different MSC mixtures were manufactured to be used in sewer systems. Experimental mixture design was used taking into consideration the properties desired for its specific use with the following characteristics; high mechanical properties equivalent to or better than those of PCC, low porosity and hydraulic conductivity and improved resistance to attack by most acids and/or salt solutions.

\section{Materials and Methods}

\subsection{Raw materials}

Sulfur: granular elemental sulfur, with purity of $99.9 \%$, was obtained from Al Ruwais refinery, United Arab Emirates (UAE). Bitumen: is an olefin hydrocarbon polymeric material, which is black oily, viscous, with specific gravity of $1.0289 \mathrm{~g} / \mathrm{cm} 3$, kinematics viscosity of $431 \mathrm{cSt}$ at $135^{\circ} \mathrm{C}$ and softening point of $48.8^{\circ} \mathrm{C}$ produced from the distillation of crude oil. Crushed sand from Ras Al Khaimah with particles size $38 \mu \mathrm{m}-4 \mathrm{~mm}$. Dune sand: obtained from Al Ain area, UAE. The most common constituent of sand is silica, with specific gravity of $2.58 \mathrm{~g} / \mathrm{cm} 3$. Ladle Furnace (LF) slag was produced by the Electric Arc Furnace process from Emirates Steel in Abu Dhabi, UAE. Ground Granulated Blast Furnace Slag (GGBFS) was obtained from Al Sharjah cement factory, UAE. 


\subsection{Sulfur modification}

Sulfur is modified by mixing elemental sulfur and the chemical stabilizer (2.5-5\% bitumen) to form a sulfur-containing polymer. To facilitate the compatibility between elemental sulfur and the bitumen, surfactant agent (Triton X-100) was used as emulsifying agent. The mixing process was maintained at about $140^{\circ} \mathrm{C}$ for a period of $45-60$ minutes, (Figure 1). Detailed description of the preparation can be found in [10]. The development of the reaction is followed by monitoring the changes in viscosity and homogeneity of the mixture. The final product is a sulfur-containing polymer, which on cooling possess glass like properties.

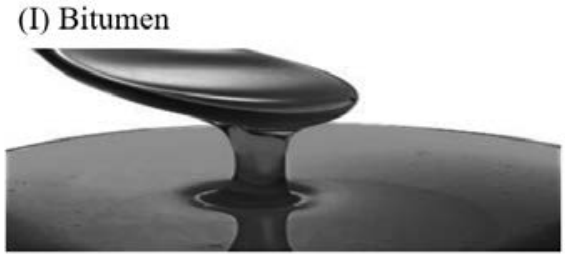

(II) Surfactant agent

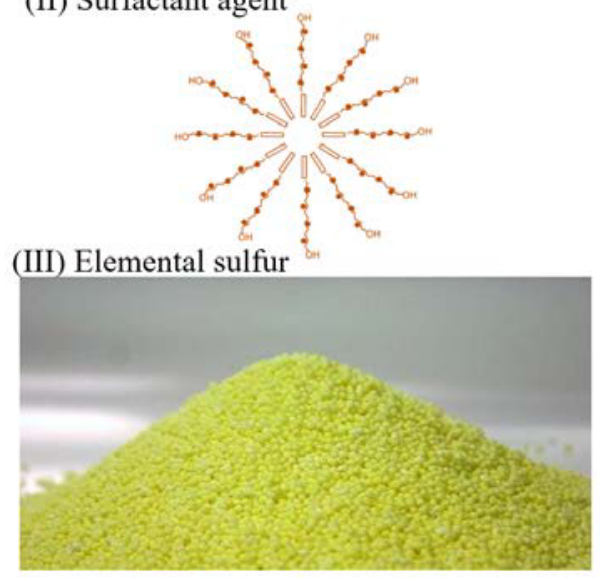

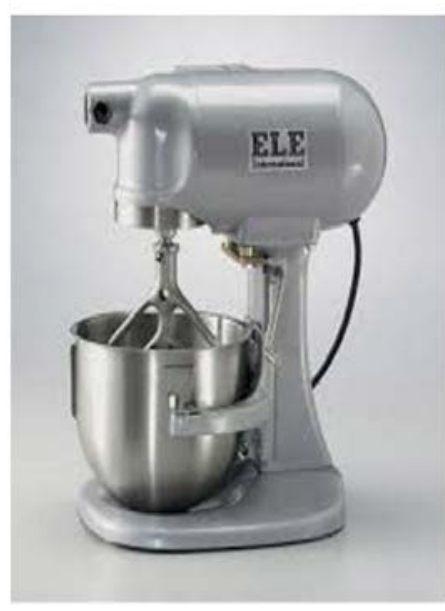

(IV) Asphalt mixer

Fig. 1. Sulfur modification.

\subsection{Production of sulfur concrete}

MSC was prepared according to the procedure described in ACI 548.2R-93 for mixing and placing sulfur concrete [11]. The preheated coarse, fine aggregates and filler were mixed with molten modified sulfur cement at controlled rate of $130-140^{\circ} \mathrm{C}$. The temperature was maintained throughout the mixing process. Finally, the hot mixture was poured in pre-heated cubic and cylindrical moulds and settled on a vibrating table for 1 minute. After curing at $40^{\circ} \mathrm{C}$ for 24 hours, the samples were kept at room temperature.

\subsection{Mixing protocol and measured responses}

To determine the mix proportions of MSC, five constituents were used; sulfur cement (X1), crushed sand (X2), Dune sand (X3), LF Slag (X4) and GGBFS (X5). The proportions of the mixture components were selected in terms of mass fraction, based on preliminary tests. The lower and upper limits of the proportions were chosen based on pre-laboratory experimental results, Table 1. 
Table 1. Lower and Upper limits of different MSC ingredients mass fraction.

\begin{tabular}{|c|c|c|c|}
\hline Constituent & ID & $\begin{array}{c}\text { Lower limit by mass } \\
\text { fraction }\end{array}$ & $\begin{array}{c}\text { Upper limit by mass } \\
\text { fraction }\end{array}$ \\
\hline Sulfur cement & $\mathrm{X} 1$ & 0.18 & 0.28 \\
\hline Crushed sand & $\mathrm{X} 2$ & 0.11 & 0.40 \\
\hline Dune sand & $\mathrm{X} 3$ & 0.13 & 0.36 \\
\hline LF slag & $\mathrm{X} 4$ & 0.05 & 0.22 \\
\hline GGBFS & $\mathrm{X} 5$ & 0.05 & 0.12 \\
\hline
\end{tabular}

MINITAB17 software was used to propose various recommended proportions to be used in the design and statistical evaluation of experimental results. MINITAB17 proposed 31 different mixtures in which the ingredients are varied as represented in Table 2. Also, in order to achieve more representative results of the components' effect, the 31 suggested mixtures were duplicated. Additional mixtures were conducted to test the developed mixture models. The successful optimization of the MSC composition requires identifying the best proportions of the materials to reach optimum mechanical response. A generalized linear model is basically a regression model. Like all regression models, it is made up of a random component and a function of the design factors (the x's) and some unknown parameters. In a standard normal-theory the response (y) in linear regression model as Eq.1

$$
y=\beta_{0}+\beta_{1} X_{1}+\beta_{2} X_{2}+\cdots+\beta_{i} X_{i}+\epsilon \cdots
$$

Where: $\mathrm{Y}$ : is the response; compressive strength, splitting tensile strength and flexural strength; $\mathrm{X} 1, \mathrm{X} 2, \ldots \mathrm{Xi}$ are the variables; sulfur cement (X1), crushed sand (X2), Dune sand (X3), LF Slag (X4) and GGBFS (X5); and $\beta 1, \beta 2, \ldots$ coefficient

This statistical design enables comparing the different mathematical regression models based on their best-fit to the experimental results. In addition, it helps identifying the significant terms of a selected mathematical model so that other insignificant terms are eliminated allowing for a simpler model. In particular, it was hypothesized that the special cubic model correlated the composition of the MSC mixture with the required characteristics. As the statistical analysis was described in details for three mechanical responses; compressive strength, splitting tensile strength and flexural strength. For each of the three responses, the model was fitted using linear (Eq. 2), quadratic (Eq.3) and special cubic (Eq. 4), respectively [12].

$$
\begin{aligned}
& E(y)=\sum_{i=1}^{p} \beta i x i \\
& E(y)=\sum_{i=1}^{p} \beta i x i+\sum \sum_{i<j}^{p} \beta i j x i x j \\
& E(y)=\sum_{i=1}^{p} \beta i x i+\sum \sum_{i<j}^{p} \beta i j x i x j+\sum \sum_{i<j<k} \sum \beta i j k x i x j x k \ldots \ldots
\end{aligned}
$$

Where: Y represents the response; the variables are; sulfur cement (X1), crushed sand (X2), Dune sand (X3), LF Slag (X4) and GGBFS (X5). 
Table 2. Proportions of MSC mixtures.

\begin{tabular}{|c|c|c|c|c|c|}
\hline $\begin{array}{c}\text { Mix } \\
\text { No. }\end{array}$ & $\begin{array}{c}\text { Sulfur } \\
\text { cement }\end{array}$ & $\begin{array}{c}\text { Crushed } \\
\text { sand }\end{array}$ & $\begin{array}{c}\text { Dune } \\
\text { sand }\end{array}$ & $\begin{array}{c}\text { LF } \\
\text { Slag }\end{array}$ & GGBFS \\
\hline 1 & 0.22 & 0.40 & 0.23 & 0.05 & 0.10 \\
\hline 2 & 0.27 & 0.11 & 0.33 & 0.22 & 0.07 \\
\hline 3 & 0.22 & 0.40 & 0.18 & 0.15 & 0.05 \\
\hline 4 & 0.18 & 0.40 & 0.17 & 0.15 & 0.10 \\
\hline 5 & 0.22 & 0.40 & 0.13 & 0.15 & 0.10 \\
\hline 6 & 0.22 & 0.38 & 0.25 & 0.05 & 0.10 \\
\hline 7 & 0.18 & 0.37 & 0.25 & 0.15 & 0.05 \\
\hline 8 & 0.22 & 0.33 & 0.25 & 0.15 & 0.05 \\
\hline 9 & 0.18 & 0.32 & 0.25 & 0.15 & 0.10 \\
\hline 10 & 0.26 & 0.15 & 0.30 & 0.18 & 0.12 \\
\hline 11 & 0.21 & 0.32 & 0.28 & 0.14 & 0.06 \\
\hline 12 & 0.22 & 0.40 & 0.25 & 0.05 & 0.08 \\
\hline 13 & 0.22 & 0.40 & 0.25 & 0.08 & 0.05 \\
\hline 14 & 0.20 & 0.40 & 0.25 & 0.05 & 0.10 \\
\hline 15 & 0.18 & 0.40 & 0.25 & 0.07 & 0.10 \\
\hline 16 & 0.22 & 0.34 & 0.24 & 0.12 & 0.08 \\
\hline 17 & 0.21 & 0.39 & 0.23 & 0.08 & 0.09 \\
\hline 18 & 0.22 & 0.30 & 0.26 & 0.15 & 0.07 \\
\hline 19 & 0.21 & 0.39 & 0.20 & 0.13 & 0.06 \\
\hline 20 & 0.24 & 0.22 & 0.25 & 0.17 & 0.11 \\
\hline 21 & 0.23 & 0.35 & 0.19 & 0.14 & 0.10 \\
\hline 22 & 0.21 & 0.38 & 0.24 & 0.08 & 0.09 \\
\hline 23 & 0.22 & 0.28 & 0.28 & 0.15 & 0.07 \\
\hline 24 & 0.21 & 0.35 & 0.24 & 0.13 & 0.06 \\
\hline 25 & 0.28 & 0.11 & 0.36 & 0.19 & 0.07 \\
\hline 26 & 0.24 & 0.24 & 0.27 & 0.15 & 0.10 \\
\hline 27 & 0.19 & 0.39 & 0.24 & 0.12 & 0.06 \\
\hline 28 & 0.21 & 0.39 & 0.24 & 0.08 & 0.08 \\
\hline 31 & 0.22 & 0.35 & 0.25 & 0.10 & 0.07 \\
\hline & 0.20 & 0.39 & 0.24 & 0.08 & 0.09 \\
\hline 0.22 & 0.31 & 0.27 & 0.10 & 0.10 \\
\hline
\end{tabular}

\subsection{Durability studies of MSC}

Specimens from the optimum MSC mixture were immersed in different solutions; water at room temperature, water at $60^{\circ} \mathrm{C}, 20 \%$ sulfuric acid solution, and $5 \%$ sodium chloride solution tank for 18 months. The reduction in compressive strength with respect to the air (un-exposed) specimens was measured. 


\section{Results and Discussion}

\subsection{Sulfur Modification}

In the modification process, bitumen, a by-product from crude oil refining process was used to modify elemental sulfur with the aid of a non-ionic surfactant agent to facilitate the compatibility between the sulfur and the bitumen. Addition of bitumen in amounts of 2.5$5 \% \mathrm{wt}$. to elemental sulfur initiates chemical reactions are dependent on the bitumen content, heating temperature and reaction time. Some competing reactions such as bitumen incorporation into sulfur molecules and/or de-hydrogenation with liberation of hydrogen sulfide could occur. The reaction of sulfur with bitumen at $140^{\circ} \mathrm{C}$ produces a mixture of polysulfide and free elemental sulfur, which held as monoclinic sulfur crystal. It is supposed that the growth of large crystals may be restricted because bitumen particles serve as nucleation sites that cause the formation of many small crystals instead of fewer large orthorhombic sulfur crystals. The resulting modified sulfur leads to sulfur solidified products that are not highly stressed and have good durability and corrosion resistance [13].

\subsection{Production of MSC}

The modified sulfur is a thermoplastic material that becomes liquid when heated above its melting point and can be mixed with aggregates. Crystallization of sulfur in this case is controlled by the relative percentage and distribution of space between aggregates and sulfur binder. The effect of modification seems to be related to the increase of degree of sulfur polymerization. Sulfur itself possesses a tendency to polymerize; the modified sulfur would thus increase this tendency or maintain it for a longer time. The quality and quantity of the aggregates have substantial effect on the properties and durability of the finished MSC. No chemical reaction is required for setting as Portland cement concrete (PCC), thus minimizing incompatibilities between binder and aggregate. The MSC offers many benefits as an alternative construction material compared to PCC.

\subsection{Collective models and analysis of variance}

In the statistical mix design, compressive strength, splitting tensile strength, flexure strength and stability are greatly influenced by the proportions of crushed sand, dune sand, LF slag, GGBFS and exist of optimum proportions of sulfur cement. These design allow us to estimate linear, quadratic (the linear + the interaction terms) and special cubic interaction effects of the components, then compare the model. Table 3 shows that, the special cubic model provides an adequate fit to MSC responses; compressive strength, splitting tensile strength and flexural strength as represented in equation No. 4. The good agreement between the predicted and experimental values verified the validity of the model along with the existence of the optimal point.

\subsection{Mechanical properties of MSC}

Mechanisms involved in preparation MSC are different from those used in PCC. MSC is a thermoplastic material that is mixed and cast hot. On solidification and cooling to ambient 
Table 3. Measured compressive, splitting tensile and flexural strength values of MSC mixes.

\begin{tabular}{|c|c|c|c|c|c|c|}
\hline \multirow[t]{2}{*}{ Mix No. } & \multicolumn{2}{|c|}{$\begin{array}{c}\text { Compressive Strength } \\
(\mathrm{MPa})\end{array}$} & \multicolumn{2}{|c|}{$\begin{array}{c}\text { Splitting Tensile Strength } \\
\text { (MPa) }\end{array}$} & \multicolumn{2}{|c|}{$\begin{array}{c}\text { Flexure Strength } \\
\text { (MPa) }\end{array}$} \\
\hline & Experimental & Prediction & Experimental & Prediction & Experimental & Prediction \\
\hline 1 & 54.5 & 55.0 & 3.66 & 3.68 & 17.08 & 17.30 \\
\hline 2 & 40.0 & 40.0 & 2.78 & 2.78 & 12.66 & 12.64 \\
\hline 3 & 50.0 & 49.3 & 3.36 & 3.31 & 16.76 & 16.53 \\
\hline 4 & 39.1 & 39.2 & 2.82 & 2.82 & 14.77 & 14.78 \\
\hline 5 & 57.0 & 55.6 & 3.91 & 3.84 & 17.92 & 17.59 \\
\hline 6 & 63.7 & 66.3 & 4.45 & 4.58 & 19.00 & 19.09 \\
\hline 7 & 55.7 & 55.9 & 3.60 & 3.59 & 16.70 & 16.78 \\
\hline 8 & 50.0 & 47.9 & 4.31 & 4.29 & 18.60 & 18.96 \\
\hline 9 & 50.0 & 50.0 & 3.62 & 3.62 & 13.47 & 13.48 \\
\hline 10 & 38.7 & 39.4 & 3.57 & 3.61 & 16.07 & 16.27 \\
\hline 11 & 56.2 & 55.7 & 3.64 & 3.67 & 17.04 & 16.90 \\
\hline 12 & 61.0 & 59.1 & 4.37 & 4.28 & 20.66 & 20.37 \\
\hline 13 & 61.3 & 62.7 & 3.91 & 4.03 & 17.05 & 17.11 \\
\hline 14 & 45.0 & 45.5 & 3.39 & 3.41 & 14.06 & 14.32 \\
\hline 15 & 47.2 & 45.9 & 3.60 & 3.54 & 18.86 & 18.43 \\
\hline 16 & 61.2 & 63.4 & 3.95 & 3.81 & 19.62 & 19.64 \\
\hline 17 & 61.7 & 59.9 & 3.95 & 3.85 & 20.30 & 19.98 \\
\hline 18 & 41.7 & 44.5 & 2.95 & 3.02 & 19.49 & 18.98 \\
\hline 19 & 53.0 & 55.8 & 3.36 & 3.47 & 16.50 & 16.47 \\
\hline 20 & 42.2 & 41.0 & 3.00 & 2.93 & 13.61 & 13.35 \\
\hline 21 & 54.6 & 59.4 & 3.53 & 3.57 & 17.61 & 18.05 \\
\hline 22 & 60.5 & 59.0 & 3.94 & 3.99 & 20.74 & 19.93 \\
\hline 23 & 47.8 & 50.2 & 3.44 & 3.44 & 16.61 & 17.59 \\
\hline 24 & 54.7 & 53.5 & 3.63 & 3.52 & 21.03 & 19.93 \\
\hline 25 & 39.0 & 38.9 & 3.13 & 3.12 & 13.07 & 13.06 \\
\hline 26 & 53.5 & 51.5 & 3.86 & 3.77 & 16.62 & 16.08 \\
\hline 27 & 53.3 & 53.3 & 3.56 & 3.56 & 17.78 & 17.88 \\
\hline 28 & 55.0 & 56.7 & 3.80 & 3.78 & 17.83 & 18.35 \\
\hline 29 & 47.4 & 48.3 & 3.24 & 3.30 & 20.85 & 21.49 \\
\hline 30 & 49.0 & 50.9 & 3.15 & 3.14 & 18.34 & 19.27 \\
\hline 31 & 44.7 & 46.0 & 3.13 & 3.19 & 18.08 & 18.35 \\
\hline
\end{tabular}


temperatures, the liquid sulfur binds the aggregate and forms a rigid MSC. The PCC is prepared at ambient temperatures and relies on chemical hydration reaction to form the concrete. Table 4 shows a comparison between mechanical properties of the prepared MSC and a typical $40 \mathrm{MPa}$ PCC. In MSC, the majority of the matrix is composed of sulfur coated aggregates and sulfur accumulating in the voids between particles leading to the reduction of the overall porosity of the MSC. The molten modified sulfur acts as binder material for these aggregates and filler. It can penetrate deeply into the gaps between coarse and fine aggregates and filler producing a strong and dense structure. Moreover, MSC solidifies and achieves its high strength because of modified sulphur, as an encapsulating agent. The fast curing of MSC contributes to shortening the construction period. MSC has high flexural and tensile strength because of the thermoplastic properties of sulfur cement. It is estimated that crushed sand and LF slag develop very strong interlocking properties leading to improved mechanical properties. GGBFS increased the density by filling the pores and better packing the particles. Sand dune enables the molten sulfur to adhere more easily on the surface of the aggregates.

Table 4. Comparison between mechanical properties of manufactured MSC and $40 \mathrm{MPa}$ PCC.

\begin{tabular}{|c|c|c|c|}
\hline Property (MPa) & Compressive Strength & Splitting Tensile & Flexure Strength \\
\hline MSC $^{*}$ & 64 & 4.5 & 21 \\
\hline PCC $^{* *}$ & 40 & 3.2 & 10 \\
\hline
\end{tabular}

* Average measured values after 3 days.

**Average measured values after 28 days.

\subsection{Statistical model for prediction of MSC strength}

The different strength values of MSC, as predicted by the special cubic model along with the corresponding experimental measurements are presented in Fig. 2a-c. The comparison between these values indicates an excellent agreement between the predicted and experimental data [14]. The maximum differences between the measured and predicted compressive strength, splitting tensile and flexural strength of the mixes are $4 \%, 3.4 \%$ and $5.2 \%$, respectively.

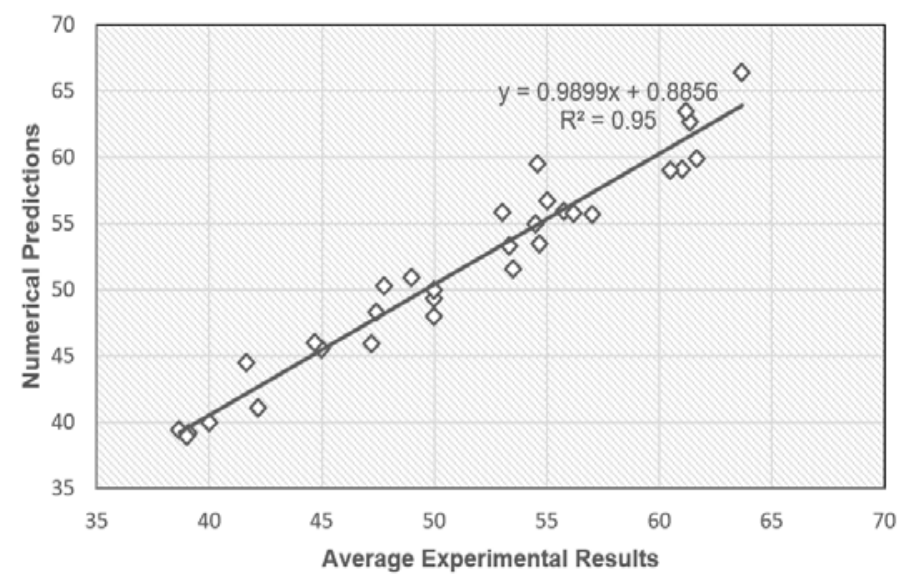

Fig. 2a. Correlation between experimental and predicted values of compressive strength for MSC.

This covenant between the predicted and experimental values validates the accuracy of the model and confirms the existence of optimal mixture. In general, the higher the R-squared, 
the better the model fits of data. The adjusted $\mathrm{R}^{2}$ is a useful tool for comparing the explanatory power of models with different numbers of predictors. The coefficient of determination $\mathrm{R}^{2}$ of the compressive strength, splitting tensile and flexural strength are $0.95,0.98$ and 0.96 , respectively, using a 5\% significance level as represented in Figs. 2a, $2 \mathrm{~b}$ and $2 \mathrm{c}$, respectively.

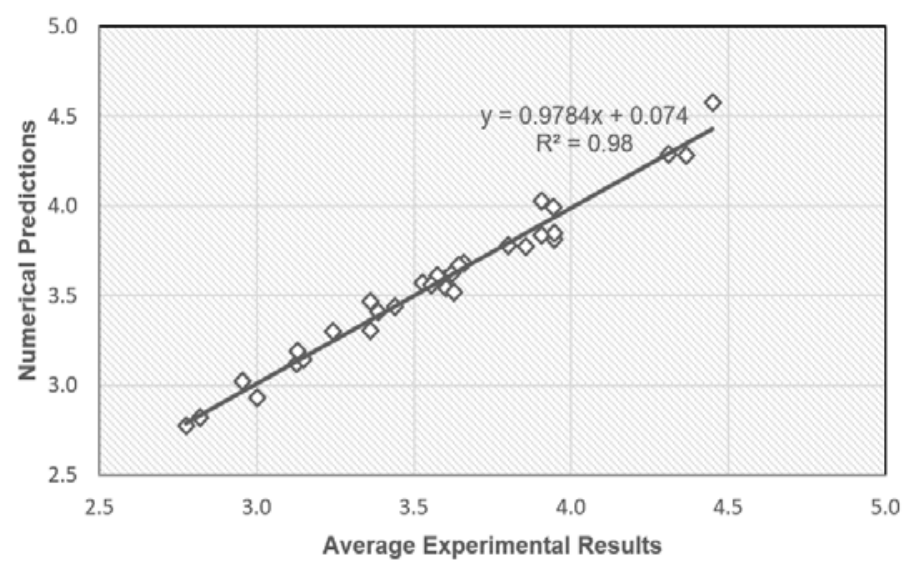

Fig. 2b. Correlation between experimental and predicted values of splitting tensile strength for MSC.

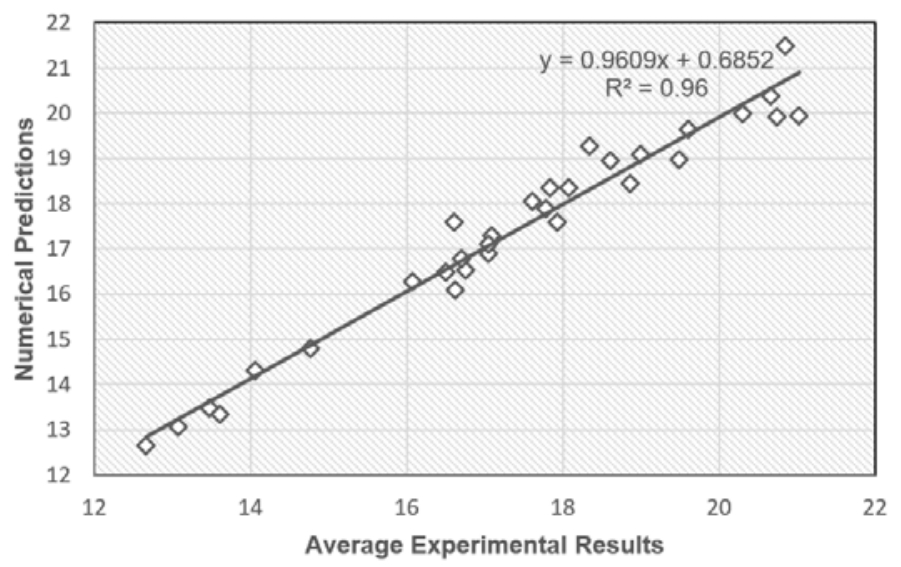

Fig. 2c. Correlation between experimental and predicted values of flexural strength for MSC.

\subsection{Durability of MSC}

Figure 3 shows the reduction in compressive strength of the optimized MSC after exposure for 18 months to different solutions; water at room temperature $\left(23 \pm 3^{\circ} \mathrm{C}\right)$, water at $60^{\circ} \mathrm{C}$, $20 \%$ sulfuric acid solution, and 5\% sodium chloride solution. Durability results indicated that the manufactured MSC has high resistance to neutral, acidic, and saline environments. 


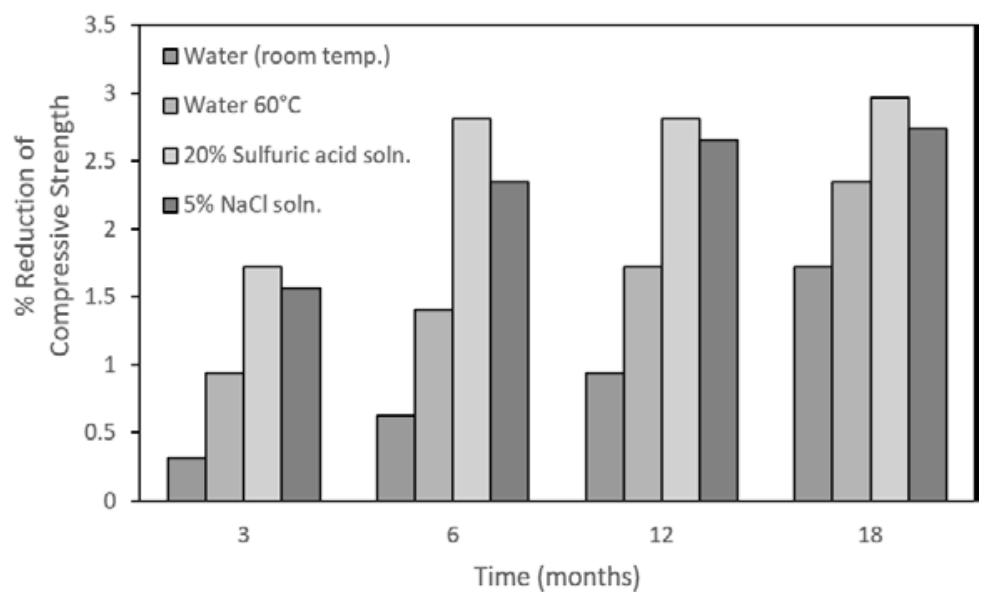

Fig. 3. Compressive strength reductions of MSC after exposure 18 months to different environments.

The least reduction in the compressive strength was observed when the MSC was exposed to distilled water at room temperature. As the water temperature increased the strength reduction also increased. Exposure to $20 \%$ sulfuric acid solution produced the highest compressive strength reduction after 3months of exposure time, then it was stabilized after 6 months and almost no further reduction occurred, which indicated a very good performance under these aggressive environments. This behaviour can be attributed to the structure of MSC where the majority of the matrixes are composed of sulfur-coated materials (aggregates and fillers). Figure 3 shows that there was a little reduction in compressive strength of MSC tested in 5\% saline solution, which can be attributed to the formation of expansive salts (e.g., Gypsum, Ettringite and Thaumasite) that resulted in loss of bonding properties [8].

\subsection{Testing of MSC Pipe}

The optimized MSC mixture No. 22, Table 2 (modified sulfur: 0.21 , crushed sand: 0.38 , dune sand: 0.24 , LF slag: 0.08 and GGBFS:0.09) was used to cast a reinforced pipe segment with outer diameter of $360 \mathrm{~mm}$, inner diameter of $300 \mathrm{~mm}$ and length of $600 \mathrm{~mm}$.
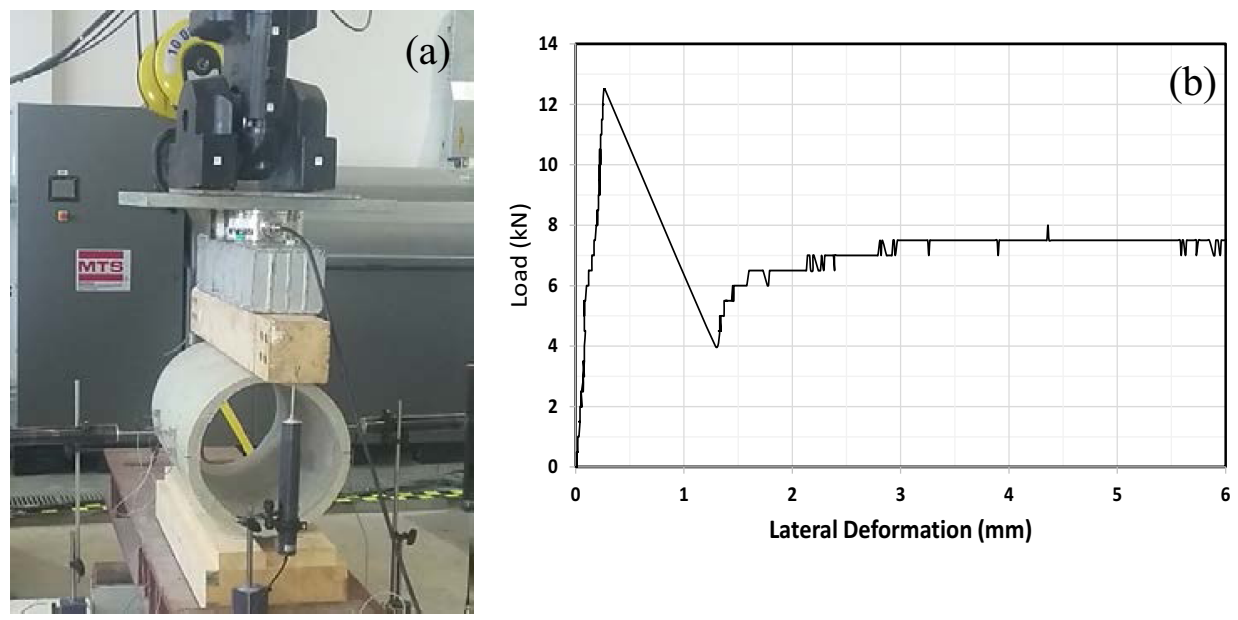

Fig. 4. (a) Testing setup and (b) load-lateral deformation curve of the produced MSC pipe segment. 
The pipe segment was tested under vertical line load and three-edge bearing standard test as per ASTM C497, as shown in Figure 4a. The reinforced MSC pipe segment tested failed under a load of $12.5 \mathrm{kN}$ and the average lateral deformation at maximum load was $0.25 \mathrm{~mm}$ as shown in Figure 4b.

\section{Conclusion}

This work describes the modification of elemental sulfur using an olefin hydrocarbon polymeric material (bitumen) which resulted in controlling crystallization of sulfur and forming a new structure with fine grain sizes. The manufacture of a MSC consisting of modified sulfur, crushed sand, dune sand, LF slag, and GGBFS was conducted using statistical experiment-based mixture design to optimize proportions of MSC in order to maximize its mechanical properties. The developed model showed good correlation between predicted and measured properties. The optimum MSC mixture showed improved resistance to harsh environments over 18 months, particularly in water at different temperatures, $20 \%$ sulfuric acid solution and 5\% sodium chloride solution. The optimized MSC mixture was used to cast a reinforced pipe segments to be used in sewer system. The pipe segment failed under a load of $12.5 \mathrm{kN}$ and lateral deformation of $0.25 \mathrm{~mm}$. The presented MSC has good potentials to be used in sewer pipes.

\section{References}

1. J. Moon, P. D. Kalb, L. Milian, P. A. Northrup, Cement and Concrete Composites, 67 (2016)

2. A.M.O. Mohamed, M. El Gamal, Sulfur Concrete for the Construction Industry: A Sustainable Development Approach: J, Ross Publishing, (2010)

3. V. Gracia, E. Vàzquez, S. Carmona, International RILEM Conference on the Use of Recycled Materials in Buildings and Structures. Nov. 8-11, Barcelona (2004).

4. P. Naufal Rizwan, Dhiwagar S. Maria Jesuraj, V. Vipin, V. Anbuvel, S. Prabhakaran IJERT, 3, 8, (2014)

5. S.L. Lin, J.S. Lai, E.S.K. Chian, 1995. Waste Management 15 (5/6), (1995)

6. A.M.O. Mohamed, M. El Gamal, US Patent App. 14/480,351(2014)

7. A.M.O. Mohamed, M. El Gamal, Environ. Geol. 53, 1 (2007)

8. A.M.O. Mohamed, A. El-Dieb, K. El-Sawy, and M. El Gamal, Environmental Geotechnics EG2 (2015)

9. N. Ciak, J. Harasymiuk, Technical Sciences, 16, 4 (2013)

10. A.M.O. Mohamed, M. El Gamal (2015) US Patent App. 20150027345 (2015)

11. ACI Committee 548, American Concrete Institute, Farmington Hills, Mich (1993).

12. D. C. Montgomery, design and analysis of experiments 8 th edition john Wiley \& sons, Inc. (2012)

13. A.M.O. Mohamed, M. El Gamal, GCC patent 0003089 (2014)

14. A. A. Jaafer, American Journal of Civil Engineering and Architecture, Vol. 1, 4 (2013) 